\title{
GAMBARAN KENAIKAN BERAT BADAN PADA AKSEPTOR KB SUNTIK 3 BULAN DI PMB BIDAN AMBARWATI CILACAP TAHUN 2020
}

\section{DESCRIPTION OF THE HUSBAND'S ROLE IN THE SELECTION OF CONTRACEPTIVE EQUIPMENT IN PMB MIDWIFE ELIS YANTI S, TASIKMALAYA REGENCY}

\author{
Nursamsiyah ${ }^{1 *}$, Siti Rohmah ${ }^{2}$ \\ ${ }^{1,2}$ Program Studi D-III Kebidanan, Fakultas Ilmu Kesehatan, Universitas Galuh \\ Jalan R.E Martadinata No.10 Ciamis 46213, Indonesia \\ *E-mail corresponding: nursamsiyah781@gmail.com \\ (Diterima: Maret 2021; disetujui April 2021; dipublish Mei 2021)
}

\begin{abstract}
ABSTRAK
Program Keluarga Berencana (KB) adalah mengatur kehamilan dengan menggunakan alat atau cara kontrasepsi. Pemakaian alat kontrasepsi yang benar dan tepat oleh pasangan usia subur dijadikan upaya untuk menunda kehamilan, menjarangkan kehamilan dan mengakhiri kehamilan (BKKBN 2010). Menurut WHO jumlah penggunaan kontrasepsi suntik di seluruh dunia yaitu sebanyak 4.000 .000 atau sekitar $45 \%$. Kontrasepsi di Indonesia paling banyak di minati yaitu kontrasepsi suntik sebesar 34,3\% (Riskesdas, 2013). Untuk mengetahui Gambaran Kenaikan Berat Badan Pada Akseptor KB Suntik Di PMB Bidan Ambarwati.,Amd.,Keb Tahun 2020". Jenis penelitian ini menggunakan penelitian deskriftif yaitu peneliti hanya memberikan gambaran objek, tidak menggeneralisasi hasilnya. Penelitian ini dilakukan dengan memberikan gambaran tentang kenaikan berat badan pada akseptor kb suntik (Sulistyoningsih, 2011). Hasil Penelitian ini didapatkan 100 akseptor yang mengalami kenaikan berat badan dengan klasifikasi berat badan ringan sebanyak 87 orang dan berat 13 orang. Berdasarkan hasil penelitian dan pembahasan maka dapat disimpulkan Gambaran Yang Mengalami Kenaikan Berat Badan Pada Akseptor KB Suntik 3 Bulan Di PMB Bidan Ambarwati Cilacap Tahun 2020 sebanyak 100 orang. Diketahui kenaikan berat badan responden dengan kategori IMT Ringan sebanyak 87 akseptor dan kategori Berat sebanyak 13 akseptor. Diharapkan bidan agar lebih meningkatkan konseling dalam pelayanan kesehatan kepada WUS sehingga ibu dapat memperoleh informasi yang mencakup yang mengalami dengan kenaikan berat badan pada akseptor kb suntik.
\end{abstract}

Kata kunci: KB suntik, kenaikan berat badan

\begin{abstract}
The Family Planning Program (KB) is the way to regulate pregnancy by using a tool or contraception method. The right and correct use of contraception method by couples of childbearing age is used as an effort to delay pregnancy, space out pregnancy and end pregnancy (BKKBN 2010). According to WHO, there are 4,000,000 or 45\% injection contraception used worldwide. The most popular contraception used in Indonesia is injection contraception as many as $34.3 \%$. To find out the description of weight gain in injection contraception acceptors at PMB Midwife Ambarwati., Amd., Keb in the year of 2020. This type of research uses descriptive research, in which the researcher only provides an overview of the object, not generalizing the results. This study was conducted by providing an overview of weight gain in injection contraception acceptors. The results of this study found that 100 acceptors who have weight gain were classified into light weight for 87 people and heavy weight gain for 13 people. Based on the result and discussion, it can be concluded that there are 100 people who have weight gain at 3-month injection contraception acceptors at PMB Midwife Ambarwati Cilacap in 2020. It is found that in the increase of body weight respondents, there are 87 acceptors in the light IMT category and 13 acceptors in the heavy category. It is expected that midwives ought to further improve counseling in health services for WUS so that mothers can obtain information including those who have weight gain toward injection contraception acceptors.
\end{abstract}

Keywords: injection contraception, weight gain 


\section{PENDAHULUAN}

Tujuan Program Keluarga Berencana (KB) adalah mengatur kehamilan dengan menggunakan alat atau cara kontrasepsi. Pemakaian alat kontrasepsi yang benar dan tepat oleh pasangan usia subur dijadikan upaya untuk menunda kehamilan, menjarangkan kehamilan dan mengakhiri kehamilan. Perkembangan program Keluarga Berencana (KB) terlihat dari banyaknya pilihan metode dan alat kontrasepsi yang tersedia, itulah sebabnya program pemakaian alat kontrasepsi menjadi tumpuan harapan untuk merealisasikan kebijakan kependudukan dalam hal pengendalian jumlah penduduk. (BKKBN, 2010).

Salah satu metode dan alat kontrasepsi di Indonesia adalah metode kontrasepsi suntik. Metode kontrasepsi suntik ini telah menjadi bagian gerakan keluarga berencana nasional serta peminatnya makin bertambah. Tingginya minat pemakai kontrasepsi suntik ini karena kepraktisan dan kepercayaan tentang ampuhnya suntikan. Cara ini diakui sebagai cara aman dan sederhana (Prawirohardjo, 2011).

Data Profile Kesehatan Indonesia tahun 2017 diperoleh cakupan KB aktif di Jawa Tengah 65,6\%. Sebanyak 62,77\% akseptor KB menggunakan kontrasepsi suntik. (Kemenkes,2018). Salah satu metode dan alat kontrasepsi di Indonesia adalah metode kontrasepsi suntik. Data Profile Kesehatan Indonesia tahun 2017 diperoleh cakupan KB aktif di Jawa Tengah 65,6\%. Sebanyak $\quad 62,77 \%$ akseptor KB menggunakan kontrasepsi suntik (Kemenkes,2018). Terdapat berbagai keuntungan pemakaian kontrasepsi dengan metode suntik diantaranya sangat efektif untuk mencegah kehamilan bila digunakan setiap 1 bulan atau 3 bulan (sesuai dengan jenis suntik KB). Kerugian dari pemakaian kontrasepsi suntik adalah terjadinya perubahan penambahan berat badan (Saifudin dkk, 2014).

Kenaikan berat badan merupakan salah satu efek samping yang sering dikeluhkan oleh akseptor KB suntik. Faktor yang mempengaruhi perubahan berat badan akseptor KB suntik adalah adanya hormon progesteron yang kuat sehingga merangsang hipotalamus lateral (Kundre R, 2015). Umur merupakan salah satu faktor seseorang untuk menjadi akseptor alat kontrasepsi, sebab umur berhubungan dengan potensi reproduksi (Nur,R 2015).

Dari data capaian Kabupaten Cilacap akseptor KB yang aktif $76 \%$. MKJP 26\% dari akseptor KB aktif. Data capaian menurut Puskesmas Cimanggu II bulan

Data yang di Cilacap Januari-Maret sebanyak 11.306 sedangkan yang mengalami kenaikan berat badan terdapat 19 orang selama waktu 1bulan. Akseptor KB Suntik tertinggi ada di puskesmas Cimanggu setelah studi pendahuluan di Puskesmas Cimanggu di dapatkan data tertinggi akseptor KB Suntik ada di PMB Bidan Ambarwati Desa Babakan. Survei pendahuluan awal ke PMB bidan Ambarwati di dapat data dari 350 akseptor KB Suntik 100 orang mengeluh kenaikan berat badan. 
METODE PENELITIAN

Jenis penelitian ini menggunakan penelitian deskriftif yaitu peneliti hanya memberikan gambaran objek. Populasi penelitian ini adalah ibu yang yang mengalami kenaikan berat badan dari pengguna akseptor kb suntik yaitu sejumlah 100 orang pada tahun 2020. Sampel penelitian ini adalah total sampling, yaitu seluruh ibu yang mengalami kenaikan berat badan sejumlah 100 orang pada tahun 2020 .

\section{HASIL DAN PEMBAHASAN}

\section{Hasil Penelitian}

Tabel 1

Distribusi Frekuensi Responden Gambaran Kenaikan Berat Badan Pada Akseptor Kb Suntik 3 Bulan Di PMB Bidan Ambarwati

Tahun 2020

\begin{tabular}{|c|c|c|c|c|c|c|c|}
\hline No & Nama & BB Awal (kg) & $\begin{array}{c}\text { BB } \\
\text { Sekarang } \\
(\mathbf{k g})\end{array}$ & $\begin{array}{c}\text { Kenaikan } \\
\text { BB (kg) }\end{array}$ & TB (m) & IMT & Klasifikasi \\
\hline 1 & Ny A & 54 & 60 & 2 & 148 & 27,3 & Ringan \\
\hline 2 & Ny. E & 55 & 58 & 3 & 150 & 25,7 & Ringan \\
\hline 3 & Ny. H & 50 & 55 & 2 & 148 & 25,1 & Ringan \\
\hline 4 & Ny. W & 55 & 60 & 5 & 149 & 27 & Ringan \\
\hline 5 & Ny. W & 53 & 58 & 5 & 150 & 25,7 & Berat \\
\hline 6 & Ny. J & 60 & 63 & 3 & 153 & 26 & Ringan \\
\hline 7 & Ny. F & 52 & 56 & 3 & 148 & 25,5 & Ringan \\
\hline 8 & Ny. S & 65 & 70 & 5 & 150 & 31,1 & Berat \\
\hline 9 & Ny. R & 60 & 65 & 5 & 155 & 25,6 & Ringan \\
\hline 10 & Ny. J & 55 & 60 & 4 & 153 & 25,6 & Ringan \\
\hline 11 & Ny. M & 56 & 60 & 4 & 152 & 25,9 & Ringan \\
\hline 12 & Ny. M & 55 & 60 & 5 & 149 & 27 & Ringan \\
\hline 13 & Ny. P & 58 & 61 & 3 & 150 & 27,1 & Berat \\
\hline 14 & Ny. S & 56 & 61 & 4 & 152 & 26,4 & Ringan \\
\hline 15 & Ny. H & 56 & 60 & 4 & 153 & 25,6 & Ringan \\
\hline 16 & Ny. D & 60 & 65 & 5 & 149 & 29,2 & Berat \\
\hline 17 & Ny. A & 55 & 57 & 3 & 150 & 25,3 & Ringan \\
\hline 18 & Ny. M & 52 & 56 & 4 & 149 & 25,2 & Ringan \\
\hline 19 & Ny. D & 52 & 55 & 3 & 148 & 25,1 & Ringan \\
\hline 20 & Ny. N & 57 & 62 & 2 & 156 & 25,4 & Ringan \\
\hline 21 & Ny. W & 54 & 59 & 5 & 153 & 25,2 & Ringan \\
\hline 22 & Ny. M & 56 & 60 & 4 & 150 & 26,6 & Ringan \\
\hline 23 & Ny. F & 53 & 58 & 5 & 149 & 26,1 & Ringan \\
\hline 24 & Ny. A & 55 & 60 & 5 & 150 & 26,6 & Ringan \\
\hline 25 & Ny. U & 53 & 57 & 4 & 150 & 25,3 & Ringan \\
\hline 26 & Ny. R & 56 & 60 & 4 & 150 & 26,6 & Ringan \\
\hline 27 & Ny. U & 53 & 56 & 5 & 148 & 25,5 & Ringan \\
\hline 28 & Ny. O & 55 & 57 & 2 & 150 & 25,3 & Ringan \\
\hline 29 & Ny. S & 55 & 58 & 3 & 152 & 25,1 & Ringan \\
\hline 30 & Ny. A & 55 & 59 & 4 & 150 & 26,2 & Ringan \\
\hline 31 & Ny. M & 58 & 60 & 2 & 153 & 25,6 & Ringan \\
\hline 32 & Ny. E & 57 & 62 & 5 & 151 & 27,1 & Berat \\
\hline 33 & Ny. Z & 54 & 59 & 5 & 150 & 26,2 & Ringan \\
\hline 34 & Ny. U & 56 & 60 & 4 & 152 & 25,9 & Ringan \\
\hline 35 & Ny. U & 59 & 64 & 5 & 155 & 26,6 & Ringan \\
\hline 36 & Ny. W & 63 & 65 & 2 & 153 & 27,7 & Berat \\
\hline 37 & Ny. H & 55 & 60 & 5 & 149 & 27 & Ringan \\
\hline 38 & Ny. F & 56 & 60 & 4 & 152 & 25,9 & Ringan \\
\hline
\end{tabular}




\begin{tabular}{|c|c|c|c|c|c|c|c|}
\hline No & Nama & BB Awal (kg) & $\begin{array}{c}\text { BB } \\
\text { Sekarang } \\
(\mathrm{kg})\end{array}$ & $\begin{array}{c}\text { Kenaikan } \\
\text { BB (kg) }\end{array}$ & TB (m) & IMT & Klasifikasi \\
\hline 39 & Ny. P & 57 & 60 & 3 & 151 & 26,3 & Ringan \\
\hline 40 & Ny. $P$ & 56 & 59 & 3 & 150 & 26,2 & Ringan \\
\hline 41 & Ny. E & 58 & 60 & 2 & 151 & 26,3 & Ringan \\
\hline 42 & Ny. F & 53 & 58 & 5 & 150 & 25,7 & Ringan \\
\hline 43 & Ny. H & 54 & 57 & 2 & 149 & 25,6 & Ringan \\
\hline 44 & Ny. A & 55 & 58 & 3 & 150 & 25,7 & Ringan \\
\hline 45 & Ny. E & 60 & 62 & 2 & 150 & 27,5 & Berat \\
\hline 46 & Ny. Y & 58 & 61 & 3 & 154 & 25,7 & Ringan \\
\hline 47 & Ny. T & 55 & 57 & 2 & 149 & 25,6 & Ringan \\
\hline 48 & Ny. L & 53 & 58 & 5 & 150 & 25,7 & Ringan \\
\hline 49 & Ny. N & 65 & 67 & 2 & 153 & 28,6 & Berat \\
\hline 50 & Ny. M & 57 & 60 & 3 & 152 & 25,9 & Ringan \\
\hline 51 & Ny. M & 52 & 55 & 3 & 148 & 25,1 & Ringan \\
\hline 52 & Ny. A & 57 & 60 & 3 & 150 & 26,6 & Ringan \\
\hline 53 & Ny. R & 55 & 60 & 5 & 151 & 26,3 & Ringan \\
\hline 54 & Ny. N & 55 & 58 & 3 & 150 & 25,7 & Ringan \\
\hline 55 & Ny. N & 59 & 61 & 2 & 150 & 27,1 & Berat \\
\hline 56 & Ny. L & 53 & 55 & 2 & 148 & 25,1 & Ringan \\
\hline 57 & Ny. M & 57 & 60 & 3 & 153 & 25,6 & Ringan \\
\hline 58 & Ny. T & 55 & 60 & 5 & 151 & 26,3 & Ringan \\
\hline 59 & Ny. S & 57 & 60 & 3 & 150 & 26,6 & Ringan \\
\hline 60 & Ny. M & 57 & 59 & 3 & 149 & 26,5 & Ringan \\
\hline 61 & Ny. K & 56 & 59 & 3 & 153 & 25,2 & Ringan \\
\hline 62 & Ny. E & 52 & 57 & 5 & 148 & 26 & Ringan \\
\hline 63 & Ny. D & 55 & 58 & 2 & 150 & 25,7 & Ringan \\
\hline 64 & Ny. O & 58 & 60 & 2 & 150 & 26,6 & Ringan \\
\hline 65 & Ny. A & 52 & 57 & 3 & 149 & 25,6 & Ringan \\
\hline 66 & Ny. N & 55 & 60 & 5 & 150 & 26,6 & Ringan \\
\hline 67 & Ny. S & 59 & 63 & 4 & 151 & 27,6 & Berat \\
\hline 68 & Ny. F & 54 & 57 & 3 & 148 & 26 & Ringan \\
\hline 69 & Ny. N & 60 & 65 & 5 & 154 & 27,4 & Berat \\
\hline 70 & Ny. I & 57 & 59 & 2 & 152 & 29,8 & Berat \\
\hline 71 & Ny. M & 58 & 60 & 2 & 153 & 25,6 & Ringan \\
\hline 72 & Ny. M & 53 & 57 & 4 & 148 & 26 & Ringan \\
\hline 73 & Ny. I & 54 & 59 & 5 & 150 & 26,2 & Ringan \\
\hline 74 & Ny. $P$ & 55 & 57 & 2 & 149 & 30,1 & Berat \\
\hline 75 & Ny. T & 62 & 65 & 3 & 153 & 27,7 & Berat \\
\hline 76 & Ny. M & 60 & 62 & 2 & 150 & 27,5 & Berat \\
\hline 77 & Ny. I & 60 & 65 & 5 & 155 & 27 & Berat \\
\hline 78 & Ny. E & 54 & 57 & 3 & 149 & 25,6 & Ringan \\
\hline 79 & Ny. S & 55 & 58 & 3 & 150 & 25,7 & Ringan \\
\hline 80 & Ny. R & 64 & 69 & 5 & 150 & 30,6 & Berat \\
\hline 81 & Ny. A & 56 & 60 & 4 & 152 & 25,9 & Ringan \\
\hline 82 & Ny. M & 55 & 58 & 3 & 150 & 25,7 & Ringan \\
\hline 83 & Ny. R & 53 & 58 & 3 & 148 & 26,4 & Ringan \\
\hline 84 & Ny. N & 52 & 57 & 5 & 149 & 25,6 & Ringan \\
\hline 85 & Ny. D & 55 & 57 & 2 & 150 & 25,6 & Ringan \\
\hline 86 & Ny. H & 50 & 55 & 5 & 148 & 25,1 & Ringan \\
\hline 87 & Ny. I & 55 & 60 & 5 & 149 & 27 & Ringan \\
\hline 88 & Ny. I & 52 & 57 & 5 & 150 & 25,3 & Ringan \\
\hline 89 & Ny. J & 65 & 67 & 2 & 153 & 28,6 & Berat \\
\hline 90 & Ny. R & 57 & 60 & 3 & 152 & 25,9 & Ringan \\
\hline 91 & Ny. M & 53 & 56 & 3 & 149 & 25,2 & Ringan \\
\hline 92 & Ny. N & 61 & 63 & 2 & 150 & 28 & Berat \\
\hline 93 & Ny. A & 63 & 65 & 2 & 149 & 29,2 & Berat \\
\hline 94 & Ny. S & 60 & 65 & 3 & 155 & 27 & Ringan \\
\hline 95 & Ny. S & 58 & 61 & 3 & 150 & 27,1 & Berat \\
\hline 96 & Ny. R & 60 & 62 & 2 & 148 & 28,3 & Berat \\
\hline 97 & Ny. F & 65 & 67 & 2 & 160 & 26,1 & Berat \\
\hline 98 & Ny. H & 55 & 58 & 3 & 150 & 25,7 & Ringan \\
\hline
\end{tabular}




\begin{tabular}{cccccccc} 
No & Nama & BB Awal (kg) & $\begin{array}{c}\text { BB } \\
\text { Sekarang } \\
\mathbf{( k g )}\end{array}$ & $\begin{array}{c}\text { Kenaikan } \\
\text { BB (kg) }\end{array}$ & TB (m) & IMT & Klasifikasi \\
\hline 99 & Ny. N & 57 & 60 & 3 & 149 & 27 & Ringan \\
100 & Ny. R & 58 & 60 & 2 & 150 & 26,6 & Ringan
\end{tabular}

Berdasarkan dari tabel di atas ibu mengalami kenaikan berat badan dengan rata-rata naik $5 \mathrm{~kg}$.

\begin{tabular}{lll} 
Klasifikasi & Jumlah & Persen \\
\hline Berat & 13 akseptor & $13 \%$ \\
Ringan & 87 akseptor & $87 \%$ \\
\hline & 100 akseptor & $100 \%$
\end{tabular}

Menurut tabel 1 menunjukan hasil bahwa klasifikasi Berat Badan Berat (13\%) dan Berat Badan Ringan (87\%).

\section{Pembahasan}

Berdasarkan hasil perhitungan di dapatkan kenaikan berat badan pada akseptor $\mathrm{KB}$ suntik 3 bulan pada responden 100 orang yaitu : 13 akseptor KB (13\%) masuk dalam klasifikasi berat dan 87 akseptor KB (87\%) masuk dalam klasifiaksi ringan. Pada tahun pertama dan meningkat 7,5 kilogram selama enam tahun. Sedangkan pemakaian DMPA berat badan meningkat rata-rata dua hingga tiga kilogram tahun pertama pemakaian dan terus bertambah selama tahun kedua (Dewi, Susilani dan Siswatibudi, H 2016). Yang mempengaruhi perubahan berat badan akseptor KB suntik yaitu dengan adanya hormon progesteron yang kuat sehingga merangsang hipotalamus lateral. Dengan adanya nafsu makan yang lebih banyak dari biasanya tubuh akan kelebihan zat-zat gizi. Kelebihan zat-zat gizi oleh hormon progesteron di rubah menjadi lemak dan disimpan di bawah kulit, perubahan berat badan ini akibat adanya penumpukan lemak yang berlebih hasil sintesa dari karbohidrat menjadi lemak.

Pada umumnya pertambahan berat badan tidak terlalu besar, bervariasi antara 1 $\mathrm{kg}$ sampai $5 \mathrm{~kg}$ dalam tahun pertama. Penyebabnya belum jelas kemungkinan disebabkan karena hormone progesterone mempermudah perubahan karbohidrat dan gula menjadi lemak sehingga lemak dibawah kulit bertambah, selain itu hormone progesterone menyebabkan nafsu makan bertambah dan menurunkan aktivitas fisik akibatnya pemakaian suntikan dapat menyebabkan perubahan berat badan. Kegemukan yang terjadi pada akseptor KB salah satu kontrasepsi yaitu suntik DMPA pada dasarnya dikarenakan hormon progesterone yang dapat menyebabkan nafsu makan bertambah apabila dosis yang tinggi dan berlebihan karena menurut para ahli DMPA merangsang pusat pengendali nafsu makan di hipotalamus yang menyebabkan akseptor makan lebih banyak dari biasanya (Rn AR, 2015).

\section{SIMPULAN}

Diketahui seluruhnya responden yang mengalami kenaikan berat badan sebanyak 100 orang $(100 \%)$. Diketahui kenaikan berat badan responden dengan kategori IMT Ringan sebanyak 87 akseptor dan kategori 
Nursamsiyah \& Siti Rohmah

Berat sebanyak 13 akseptor. Diketahui kaenaikan berat badan di pengaruhi oleh hormon progesteron yang terkandung dalam KB suntik DMPA 3 Bulan.

\section{DAFTAR PUSTAKA}

BKKBN. (2010) Buku Panduan Praktis Pelayanan Kontrasepsi. Jakarta : PT Bina Pustaka Sarwono Prawihardjo

Kemenkes RI. 2018. Profil Kesehatan Indonesia 2017. Jakarta: Kemenkes RI.

Nur R, R, N. (2017). Penggunaan Kontrasepsi Dan Perubahan Berat Badan Akseptor Kb. 2017 September. Rn AR. (2015). Penggunaan Kontrasepsi Dan Perubahan Berat Badan Akseptor KB; 2015. 